\title{
The Impact of Teaching Vocabulary through "Kik" Application on Improving Intermediate EFL Learner's Vocabulary Learning
}

\author{
Saeedeh Rajayi ${ }^{1, *}$, Mahpareh Poorahmadi ${ }^{2} \&$ Mahpare Poorahmadi $^{2}$ \\ ${ }^{1}$ Faculty of Persian Literature and Foreign Languages, Roudehen Branch, Islamic Azad University Roudehen, Iran \\ ${ }^{2}$ English Language Teaching (ELT) Department, Faculty of Persian Literature and Foreign Languages, Roudehen \\ Branch, Islamic Azad University Roudehen, Iran \\ *Correspondence: Faculty of Persian Literature and Foreign Languages, Roudehen Branch, Islamic Azad University \\ Roudehen, Iran. E-mail: Sahar_rajayi2013@yahoo.com
}

Received: October 20, 2017

Accepted: November 11, 2017 Online Published: January 5, 2018

doi:10.5430/ijelt.v5n1p22

URL: https://doi.org/10.5430/ijelt.v5n1p22

\begin{abstract}
A considerable body of research has been conducted on effective vocabulary instruction to improve vocabulary learning. However, no research has been done to empirically document the link between teaching vocabulary through "Kik' application and vocabulary learning. Thus, this study was conducted to fill this gap in research related to this phenomenon. To this effect, 61 intermediate EFL learners from Joyandegan language institute were selected through convenience sampling and randomly assigned to two groups; experimental and control group. In this pretest, posttest experimental study, only the experimental group received training through "Kik" application. The comparison of the scores of Teacher Made Vocabulary Test showed that the scores of experimental group were higher than those of the control group. The comparison of the scores of Teacher Made Vocabulary Test showed that the scores of experimental group were higher than those of the control group. This provided a statistically significant relationship between the independent variable, teaching vocabulary through "Kik" application, and vocabulary learning which is the dependent variable. The results of this study point to a probability that on using of "Kik" for teaching vocabulary and the results of this study showed that using "Kik" for teaching can have a significant impact on EFL learners' vocabulary learning.
\end{abstract}

Keywords: social networks, social media technology, vocabulary learning, EFL learners, "Kik" application

\section{Introduction}

Vocabulary as one of the component skills seems to play a critical role in language achievement. It can be said that without words that label objects, actions, and concepts, a speaker cannot express intended meanings (Kitajima, 2001).Words are the units of meaning. Sentences, paragraphs, and whole texts are derived from words. Language ability is often considered as the number of words that are known. Thus, vocabulary teaching/learning is a critical area that needs paying special attention (Knight, 1994).

Undoubtedly technology has impacted and influenced the lives of everyone more or less. In recent years, advancement and ease of using technology has made everyone wonder how technology can improve the way we do things. Applying technology to learning and teaching a second or foreign language is an important educational issue (Kruidenier, 2002).

Some mobile applications can be considered as an interesting tool for teaching second language especially teaching L2 words. The education community still continues to challenge to establish the role that some mobile applications can play in effective language teaching and learning. Students come to classes as all equipped with the newest technologies available, but often they have to leave them at the door (Roblyer, 2010), because the field still looks to lack a unified theory and scope of the uses of social networks in language pedagogy.

The aim of current study was to explore the impact of teaching vocabulary through "Kik" application on improving intermediate EFL learners' vocabulary learning. "Kik" is a new application that is quickly changing how people use their phones. "Kik" is known for its features preserving users' anonymity, such as allowing users to register without 
providing a telephone number, and preventing users from being located on the service (including by the company itself) through any information other than their chosen username (Rahman, 2016). Regarding to the aim of this study, following research question is addressed:

1. Does teaching vocabulary through "Kik" application have any significant effects on intermediate EFL learners' vocabulary learning?

2. Review of the Related Literature

This section deals with theoretical and empirical works about the impact of teaching vocabulary through "Kik" application on improving EFL learners' vocabulary learning.

\subsection{Vocabulary}

"Little can be transferred if one does not know grammar, but nothing can be transferred if one does not know any vocabulary" (Wilkins 1972, p.111). The importance of vocabulary learning is clear. Listening, speaking, reading and writing vocabulary items can aid students learn the new words. Vocabulary knowledge is the important element of language learning. It is impossible to ignore the power of words (Pilkulski \& Templeton, 2004). Vocabulary is the main way for learning a language. Words are the blocks of a language. Vocabulary is an important component of language use. The significant effect of vocabulary knowledge on second or foreign language learning has been stressed recently (Zahedi \& Abdi, 2012). Since vocabulary has a great influence on students' proficiency and their production and comprehension of language (Gathercole, 2006), it can be said that "learning a second language means learning its vocabulary" (Gass, 1999, p.123).

\subsection{Social Networks Application}

The advent of digital age has altered the way people communicate in the last decades. Whether in the form of emails or social networks (SNs), technology has been combined with communication to challenge the way individuals associate with one another (Scarborough, 2009).

Using social networks in educational and instructional contexts can be regarded as a potentially powerful idea simply because students spend a lot of time on these online networking activities (Mazman, 2010). Mason and Rennie (2007) pointed that it is no longer a question of whether to take advantage of these electronic technologies in foreign language teaching or not, the question is how to promote students' learning using them. Studies showed that social network tools support educational activities by making interaction, collaboration, active participation, information and resource sharing, and critical thinking possible (Mason, 2006).

\subsection{Kik" Application}

"Kik" is often a wise phone application that lets individuals use Wi-Fi to email texts. It's really a mix platform application, and that means you will utilize "Kik" for PC or Mac and may take benefits of "Kik" for computer communication. Weight loss artists are utilizing their Wise Phones her or his primary Internet device, programs like Kik will probably grow in learning. Before utilizing "Kik", you should download the applying in the Kik website. Really the only challenge with Kik is the fact you will require a Wi-Fi link with really make money. However, this may be a small caveat, as Wi-Fi signals have grown to be ubiquitous around the world. "Kik" is a new application that is quickly changing how people use their phones. It's a multi-platform application, so it can be used for PCs, Mac and general computer applications. Users simply can download it using a Wi-Fi link in order to enjoy its services (Rahman, 2016).

\subsection{Empirical Studies}

In his study, Chalak (2016) examine the role of What's App on Iranian EFL learners' vocabulary knowledge. This study aimed to investigate the role of WhatsApp in the vocabulary learning improvement of Iranian junior high school EFL students. By using a mixed method design, a group of 60 students including 30 male and 30 female students studying at two male and female junior high schools in Isfahan, Iran were participated in the study. A pre-test and post-test were used. Four English classes were instructed and the experimental group received vocabulary instructions electronically four days a week for four weeks using the WhatsApp while the control group was taught vocabularies of their textbook inside the classroom by traditional method used in all Iranian schools for teaching English to students. The results showed that using WhatsApp had significant role in vocabulary learning of the students. The results also showed that there was not a substantial difference between male and female students regarding their vocabulary knowledge after using WhatsApp. The findings of this study can be beneficial to Iranian EFL students, teachers, language schools, policy makers, and syllabus designers.

In their study, Tamjid and Moghadam (2012) performed an experimental study to investigate the effects of Narsis 
software on Iranian intermediate EFL learners' vocabulary acquisition. To this end, 46 homogeneous intermediate EFL learners were invited to participate in this study. They were randomly assigned to experimental and control groups. The experimental group received the treatment by Narsis software which was based on "504 Absolutely Essential Words" book over a one-month period of time. The control group was taught the same vocabulary by traditional method. After the treatment, both groups sat for the same posttest. The analysis of the results showed that the experimental group outperformed the other group and the participants in the experimental group (through interviewing) had positive attitudes towards Narsis software.

\section{Method}

\subsection{Research Design}

The quantitative study was conducted using a quasi-experimental design as there is no true randomization. This kind of design is appropriate for this study as it allows the researcher to have control over the assignment and it lacks the element of random assignment to treatment while the interventions are existed in the classes.

Table 1. Research Design: Pre-test and Post-test Control Group and Experimental Group Design

\begin{tabular}{lllll}
\hline Experimental Group & A & T1 & X & T2 \\
\hline Control Group & B & T1 & & T2 \\
$($ X = intervention, T1 $=$ Pre-test, $\mathbf{T} 2=$ Post-test $)$ & & \\
\hline
\end{tabular}

\subsection{Participants}

This study was conducted in Joyandegan English Institute in Tehran province. The participants comprised of 90 intermediate Iranian EFL learners whom had to undergo PET (2003), to establish homogenization. Accordingly, students whose score fell between one standard deviation above and below the means were accepted to be the participants for this study. Consequently, only 29 students were excluded and removed from the study and the rest were divided into two groups of experimental with 31 Iranian EFL students and control group with 30 Iranian EFL students. The participants were the members of six intact classes. All participants were female aged between 13 to 17 who had studied English for 3 to 4 years; and currently studying the book "Four Corners" in accordance with the principles set by the aforementioned English institute.

\subsection{Instruments}

To fulfill any research requirements, correct instruments were used to get the best result. Preliminary English Test (PET) and Teacher Made Vocabulary Test as pretest and posttest were the instruments of this study. The following sections discuss about each of these instruments in detail.

One of the instruments used to measure the homogenizing of the participants based on their language proficiency as well as to minimize the individual differences was Preliminary English Test (PET). The piloting stage of PET was originally published by Cambridge English for Speakers of Other Language (ESOL, 2009). The PET consisted of four sections: reading ( 35 items), writing ( 8 items), listening ( 25 items), and speaking ( 4 items).

In order to leave out any assumptions, a pretest was administered to evaluate the participants' possible tacit knowledge of knowing the meaning of the vocabularies before the actual intervention. The Teacher-Made Vocabulary Test used as a pretest, was designed according to "Four corners" book. This test included 80 multiple choices questions. The reliability of this text estimated and it turned out to be .85 .

Prior to the intervention, participants had to undergo pretest. Then, after the instruction, Teacher-Made Vocabulary Test as posttest was administered (. The items of this test contain similar materials to pretest items. Pretest and posttest were the same and the only difference was that 15 high frequency items in pretest were removed. Therefore, to measure the participants' vocabulary learning, a 65 multiple -choice items was used and the reliability of the test was estimated through KR-21 method and it was .84.

\subsection{Procedure and Data Analysis}

This research used Preliminary English Test (PET) which was used as a standardized measurement to seek the level of the subjects in terms of language proficiency. The result of this standard proficiency test was used to specify the 
homogeneity of the sample and equality of sample before assigning them into two equal groups prior to the commencement of the intervention program. Then, the researcher divided the participants into two groups: experimental group and control group. The participants were the members of intact classes: researcher had six intact classes. Experimental group included 31 EFL students and control group included 30 EFL students. 80 words were selected from "Four corners" book as teaching materials. The Teacher Made Vocabulary Test was administered as a pretest to evaluate the participants' possible tacit knowledge of knowing the meaning of the vocabularies before the actual intervention. This test consisted of 80 multiple choices items. Then, 15 high frequency items were removed from teaching course and posttest. The researcher of the present study taught vocabulary to the students of both groups within 12 sessions. Each session lasted 90 minutes and the researcher devoted 15 to 20 minutes of each session to teaching vocabularies to students. In each session, 5 to 6 words were taught. Definition and matching were the strategies of teaching that were employed in this study. The control group received similar training as experimental group. For example, number of sessions, the number of vocabularies, and the objective of vocabulary learning training received equal attention as experimental group. However, the main variable was kept away from this group and no "Kik" application was used in this class in all accounts.

To investigate the effect of teaching vocabulary through "Kik" application on intermediate EFL learners' vocabulary learning, the scores obtained from the proficiency, pre-test and post-test were analyzed using SPSS Version 18.0. Independent sample t-test was performed to compare the vocabulary measures of the two groups on the pre-test so as to ensure that the participants of the two groups had the same vocabulary knowledge before experiencing the treatments of this study. And finally, in order to test the hypnoses of the study, the students' vocabulary learning scores of the two groups on the post-test were compared using independent samples t-test.

\section{Results}

The aim of this study was to examine the effect of teaching vocabulary through "Kik" application on intermediate EFL learners' vocabulary learning. In this respect following research question was addressed:

1. Does teaching vocabulary through "Kik" application have any significant effect on intermediate EFL learners' vocabulary learning?

To answer this research question, two independent sample t-tests were executed comparing the mean score of vocabulary learning for the experimental and control groups on both pretest and posttest.

In the study of (Pallant, 2011, p.12), "An independent samples t-test is used when you want to compare the mean score on some continuous variable for two different groups of participants." In fact, there were two groups (i.e. experimental and control) in this study and the researcher wanted to compare the mean score of vocabulary learning in the two groups.

Table 2. Descriptive Statistics of Experimental and Control Groups' Vocabulary Learning

\begin{tabular}{lllll}
\hline Group & $N$ & Mean & $S D$ & Std. Error Mean \\
\hline Experimental & 31 & 19.97 & 3.647 & .655 \\
Control & 30 & 20.53 & 4.191 & .765 \\
\hline
\end{tabular}

Table 3. Independent Samples T-Test for Comparing Two Groups' Scores of Vocabulary Learning (Pretest)

\begin{tabular}{|c|c|c|c|c|c|c|}
\hline \multicolumn{3}{|l|}{ Levene's Test for Variances } & \multicolumn{4}{|c|}{ T-test for Means } \\
\hline & & & \multirow[t]{2}{*}{$t$} & \multirow[t]{2}{*}{$d f$} & \multirow[t]{2}{*}{ Sig. (2-tailed) } & \multirow[b]{2}{*}{ Mean Diff. } \\
\hline Factor & $F$ & Sig. & & & & \\
\hline Equal variances assumed & .329 & .568 & -.563 & 59 & .575 & -.566 \\
\hline Equal variances not assume & & & -.562 & 57.318 & .576 & -.566 \\
\hline
\end{tabular}

A look at Table 3 above reveals that $t$-value and significance level $(t(59)=.56, p=.57, p>.05)$ are signs of no statistically significant difference in vocabulary learning scores for the Experimental Group $(\bar{x}=19.97)$ and Control Group $(\bar{x}=20.53)$ (Table 2) in which the $t$-value (.56) is lower than the $t$-critical of 2.00. This shows that the students in the two groups have almost the same vocabulary knowledge at the beginning of the study. 
Table 4. Descriptive Statistics of Experimental and Control Groups' Vocabulary Learning Scores on the Posttest

\begin{tabular}{lllll}
\hline Group & $\mathrm{N}$ & Mean & SD & Std. Error Mean \\
\hline Experimental & 31 & 42.16 & 7.448 & 1.338 \\
Control & 30 & 37.47 & 6.642 & 1.213 \\
\hline
\end{tabular}

Table 5. Independent Samples Test for Comparing Two Groups' Scores of Vocabulary Learning (Posttest)

\begin{tabular}{|c|c|c|c|c|c|c|}
\hline Levene's Test for Variances & & & T-test & Means & & \\
\hline Factor & $F$ & Sig. & $t$ & $d f$ & $\begin{array}{l}\text { Sig. } \\
\text { (2-tailed) }\end{array}$ & Mean Diff. \\
\hline Equal variances assumed & .125 & .725 & 2.595 & 59 & .012 & 4.695 \\
\hline Equal variances not assumed & & & 2.600 & 58.617 & .012 & 4.695 \\
\hline
\end{tabular}

Table 5 indicates that the significance level (.72) related to Levene's value is greater than the selected significance level (.05). Furthermore, the independent samples t-test reveals that there is a statistically significant difference $(t(59)$ $=2.59, p=.01, p<.05)$ in vocabulary learning measures for the Experimental Group $(\bar{x}=42.16)$ who experienced vocabulary instruction through "Kik" application, and control group $(\bar{x}=37.47)$ who received vocabulary instruction in the conventional way. Moreover, the $t$-observed (2.59) is bigger than the $t$-critical (2.00). As a result, the null hypothesis of the current study that states, "Teaching vocabulary through "Kik" has no significant effect on intermediate EFL learners' vocabulary learning" is rejected and it can be claimed that teaching vocabulary through "Kik" improves intermediate EFL learners' vocabulary learning.

A line chart was made in order to demonstrate the results of both pretest and posttest of vocabulary learning for both groups graphically. As can be seen clearly from Figure 1, the means of two groups show an upward trend from pretest to posttest of vocabulary learning. Actually, Figure 1 shows that the mean score of vocabulary learning for the two groups are almost the same on the pretest, though the mean for the Experimental Group is significantly higher than the Control Group on the posttest of vocabulary learning.

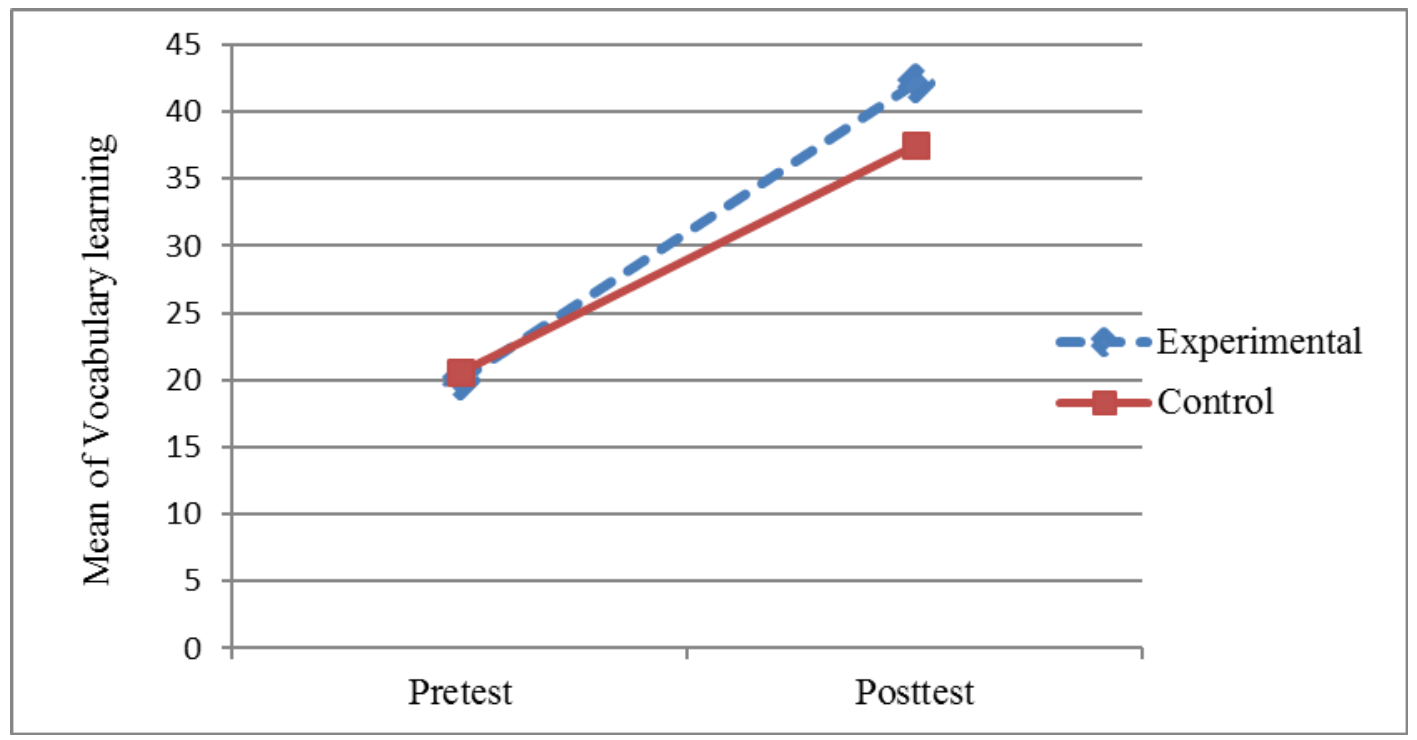

Figure 1. Two Groups’ Means of Vocabulary Learning (pretest \& posttest)

\section{Discussion and Conclusion}

The main goal of this study was to examine the impact of teaching vocabulary through "Kik" application on improving EFL learners' vocabulary learning. In order to seek the effect of the intervention program of teaching vocabulary through "Kik" application on EFL learners' vocabulary learning, the experimental group was trained by the use of this application while the control group continued with their conventional method. Then pre and posttest 
scores of their vocabulary learning that were recorded prior and subsequent to the treatment phase were analyzed. The statistics of the paired samples t-test results indicated that there was a statistically significant difference in vocabulary learning measures for the experimental group, who experienced vocabulary instruction through "Kik" application, and control group, who received vocabulary instruction in the conventional way. As a results, the hypothesis of the current study that states: "Teaching vocabulary through "Kik" has no significant effect on intermediate EFL learners' vocabulary learning" was rejected and it was claimed that the teaching vocabulary through "Kik" application has significant effect on vocabulary learning. In other words, the intervention program (using "Kik" application) was effective in improving Iranian EFL learners' vocabulary learning.

The literature review showed that in most cases, the achievement gap between EFL students of differing language proficiency levels is one of the most persistent and frustrating problems which is due to their limited knowledge of vocabulary (Chalak, 2016). To rectify such problems, a consistent and persistent investment in vocabulary development can be a good solution, which can be implemented through a variety of ways (Ebbers \& Denton, 2008). Thus, it is believed that without intervention, literacy deficits in language learners' early years of education will follow a downward spiral as they progress into one level of language proficiency into another (Nicolae, 2005). Also, a high correlation in the research literature of using social networks with improving EFL learners' vocabulary learning (Nicolae, 2005) was seen indicating the effectiveness of online tools on vocabulary learning. Thus, one aim of this study was to introduce an intervention program (i.e., "Kik" application) related to vocabulary development and to seek its effectiveness/if any on vocabulary learning.

This results of this study were in line with Horst, Cobb, and Nicolae (2005)'s work on the effectiveness of online tools on vocabulary learning and learning. Also, the results reiterate the idea that improvements in technology have greatly contributed to advances in the understanding and research in vocabulary learning. The effectiveness of using social networks on improving vocabulary learning is also stressed here and echoes similar related studies (Girgin, 2011, Kabilan et. al, 2010; Vandewaetere \& Desmet, 2009) and the results were in contrast with some other studies (Namaghi \& Malekpur, 2015) that they proved ineffectiveness of social networks in vocabulary learning. They proved using social networks can be considered as distractive factor.

The findings have important pedagogical implications. The use of online learning materials can be regarded as an effective medium for learning vocabulary and it is essential to put into consideration the pedagogies of teaching and learning vocabulary. Interwoven with these pedagogies are guiding rules when designing online materials. This section will depict some of the most prominent principles in the domain of vocabulary learning and teaching.

Mobile applications can bring a wide range of technological possibilities to a classroom. Language learners also can increase their vocabulary knowledge by simply using "Kik". "Kik" can help the language learners to find the implementation of the words and practice the words after learning.

\section{References}

Chalak, A. (2016). The role of whats app in teaching vocabulary to Iranian EFL learners at junior high school. English Language Teaching, 9(8), 85. https://doi.org/10.5539/elt.v9n8p85

Ebbers, S.M., \& Denton, C.A. (2008). A root awakening: Vocabulary instruction for older students with reading difficulties. Learning Disabilities Research \& Practice, 23(2), 90-102. https://doi.org/10.1111/j.1540-5826.2008.00267.x

Gass, S. (1999). Incidental vocabulary learning. SSLA, 21, 319-333.

Gathercole, S. (2006). Complexities and constraints in non-word repetition and word learning. Applied Psycholinguistics, 27(4), 513-543.

Girgin, E. G. (2011). A web 2.0 tool for language teaching with flash content. Procedia Computer Science, 3, 627-631. https://doi.org/10.1016/j.procs.2010.12.105

Horst, M., Cobb, T., \& Nicolae, I. (2005). Expanding academic vocabulary with an interactive on-line database. Language Learning and Technology, 9, 90-110.

Kabilan, M. K., Ahmad, N., \& Zainol Abidin, M. J. (2010). Facebook: An online environment for learning of English in institutions of higher education? Internet and Higher Education, 13, 179-187. https://doi.org/10.1016/j.iheduc.2010.07.003

Kitajima, R (2001). The effect of instructional conditions on students' vocabulary retention. Foreign Language 
Annals 34(5), 470- 483. https://doi.org/10.1111/j.1944-9720.2001.tb02086.x

Knight, S. (1994). Dictionary use while reading: The effects on comprehension and vocabulary acquisition for students of different verbal abilities. ModerLanguage Journal, 78(3), 285-299. https://doi.org/10.1111/j.1540-4781.1994.tb02043.x

Kruidenier, K. (2002). Research-based principles for adult basic education reading instruction (Contract no. ED-01-PO-1037). Retrieved from National Institute for Literacy website: http://lincs.ed.gov/publications/pdf/adult_ed_02.pdf

Mason, R., \& Rennie. F. (2007). Using Web 2.0 for learning in the community. Internet and Higher Education, 10, 196-203. https://doi.org/10.1016/j.iheduc.2007.06.003

Mazman, S.G., \& Usluel, Y.K. (2010). Modeling educational usage of facebook Computers \& Education, 55, 444-453. https://doi.org/10.1016/j.compedu.2010.02.008

Namaghi, S. A., \& Malekpur, A. (2015). Vocabulary learning strategies from the bottom-pp: A grounded theory. The Reading Matrix: An International Online Journal, 15(2).

Pallant, J. (2011). SPSS Survival manual. (4th ed.). Allen \& Unwin. NSW.

Pikulski, J. J., \& Templeton, S. (2004). Teaching and developing vocabulary: Key long-term reading success. Houghton Mifflin Reading.

Rahman, K (2016). A multimedia approach to academic listening. TESOL Journal, 6(2), 24-28.

Roblyer, M. D., McDaniel, M., Webb, M., Herman, J., \& Witty, J. V. (2010). Findings on Facebook In Higher Education: A Comparison of College Faculty and Student Uses and Perceptions of Social Networking Sites. The Internet and Higher Education, 13(3), 134-140. https://doi.org/10.1016/j.iheduc.2010.03.002

Scarborough, H. S. (2009). Approaching difficulties in literacy development: Assessment, pedagogy and programs, (1 ed., 23-38).

Tamjid, N. H., \& Moghadam, S. (2012). The effect of using vocabulary teaching software on Iranian intermediate EFL learners' vocabulary acquisition. World Applied Sciences Journal, 19(3), 387-394.

Vandewaeterea, M., \& Desmet, P. (2009). Introducing psychometrical validation of questionnaires in CALL research: The case of measuring attitude towards CALL. Computer Assisted Language Learning, 22, 349-80. https://doi.org/10.1080/09588220903186547

Wilkins, D. A. (1972). Linguistics in language teaching. Australia: Edward Arnold.

Zahedi, Y., \& Abdi, M. (2012). The effect of semantic mapping strategy on EFL learners' vocabulary learning. Procedia Social and Behavioral Sciences, 69, 2273-2280. https://doi.org/10.1016/j.sbspro.2012.12.198 